\title{
Numerical Analysis of the Resonant Cavities in Series for Optical Filter Applications
}

\author{
João Victor Marangoni*, Marcos Sérgio Gonçalves
}

\begin{abstract}
This project presents the design of an integrated optical filter developed through the integration of Finite Element Method - FEM and Genetic Algorithm - AG. The filter was carried out by association of photonic crystals microcavities and optical couplers. Numerical results shows that the filter has features that make it suitable for DWDM systems.
\end{abstract}

\section{Key words:}

Optical Filters, DWDM systems, Photonic Crystal

\section{Introduction}

Optical transmissions with multiple channels in an optical fiber need technologies that take advantage of the huge bandwidth available. For this reason, Dense Wavelength Division Multiplexing (DWDM) systems are being developed in accordance with ITU (International Telecommunication Union). In these systems, optical filters are essential elements responsible for the attenuation of noise and for the selection of an optical channel.

To be attractive, the filters must meet some characteristics, such as bandwidth compatible with the spacings between the channels and geometry that allows the manufacture in large scale in a same optical circuit. This paper aims to demonstrate the numerical analysis of a new optical filter with high selectivity. The proposed optical filter consists of the association of microcavities formed by photonic crystals [1]. For integration with conventional optical circuits, coupling between the microcavity and continuous waveguides was taken into account. The designs of the optical couplers were idealized through the Finite Element Method - FEM and the Genetic Algorithm - GA [2].

\section{Results and Discussion}

Figure 1 shows the optical filter development.

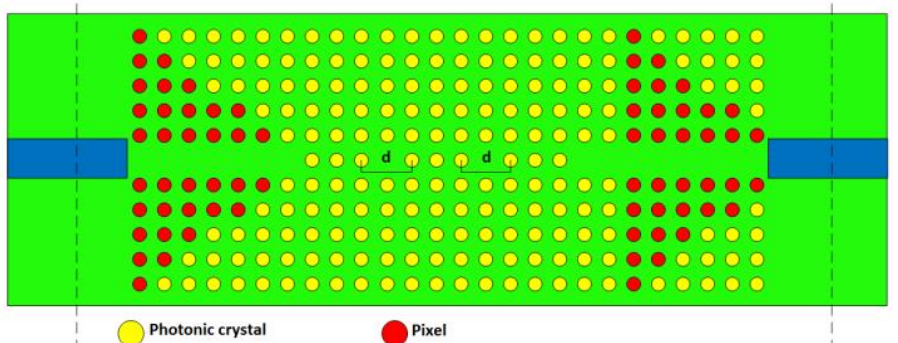

Figure 1. Proposed scheme for optical filter.

The architecture of the device is formed by two optical couplers and by series microcavities. The crystals are formed by dielectric columns with a refractive index of 3.4 , radius $0.1044 \mu \mathrm{m}$ and periodicity of $0.58 \mu \mathrm{m}$. Two wavelengths were present in the ITU-T grid, $1.551093 \mu \mathrm{m}$ and $1.568745 \mu \mathrm{m}$. Figure 2 shows the transmissivity of the optical filter to $1.551093 \mu \mathrm{m}$. Factors such as Coefficient of Transmission ( $T$ ) and Insertion Loss was considered.

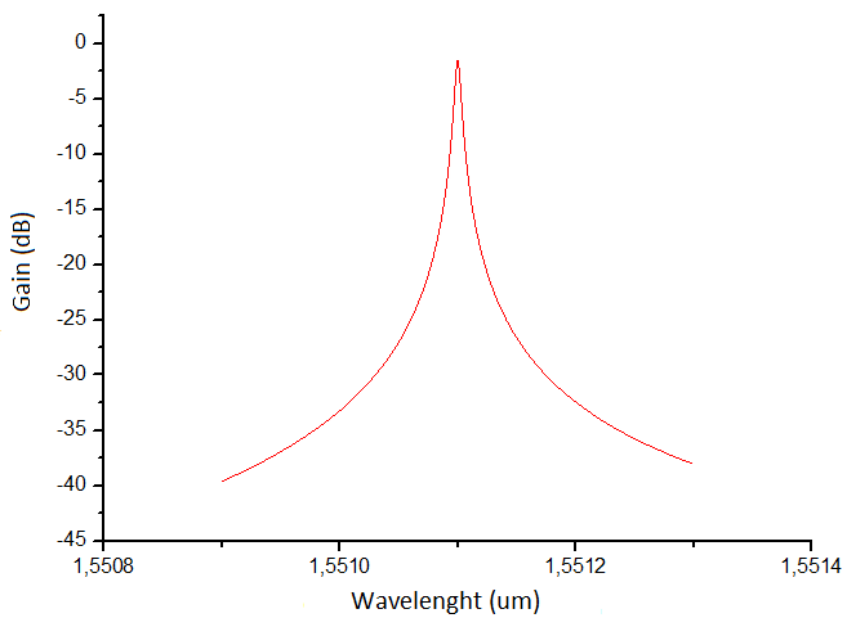

Figure 2. Optical filter transmissivity.

Table 1. Simulation data.

\begin{tabular}{|c|c|c|c|}
\hline Cavities & $\lambda(\mu \mathrm{m})$ & $\mathrm{T}(\%)$ & Loss $(\mathrm{dB})$ \\
\hline \multirow{2}{*}{2} & 1,551093 & 71,59 & 2,9 \\
\cline { 2 - 4 } & 1,568745 & 77,29 & 2,23 \\
\hline \multirow{2}{*}{3} & 1,551093 & 84,41 & 1,47 \\
\cline { 2 - 4 } & 1,568745 & 92,01 & 0,72 \\
\hline
\end{tabular}

\section{Conclusions}

Through the integration of FEM and GA and using waveguides with resonant cavities made from photonic crystals, it was possible to develop a methodology that allows designing and investigating the characteristics of the proposed optical filter. It was verified that the filter has low insertion loss and high quality factor above $1 \times 10^{\wedge} 4$.It is worth to note the use of optical couplers that improved the selectivity and presented good performance in the optical coupling between the waveguides photonic crystals.

\section{Acknowledgement}

The authors thank FAEPEX, CNPq and FAPESP for the 2011 / 12792-3 process and the financial incentive during the research.

${ }^{1}$ J.V. Marangoni, M.S. Gonçalves, IEEE Latin America Transactions. Vol. 14, No. 4, April, 2016.

${ }^{2}$ M.S. Gonçalves, H.E.H. Figueroa, C.H.S. Santos, IEEE Photon. Technol. Letters, Vol. 22, No. 15, August, 2010. 